\title{
Editorial
}

\section{Caution: changing education, changing technology}

The theme of our very successful ALT-C 95 was Changing Education, Changing Technology. The papers which made up the conference (a small selection of which are published in this special issue of $A L T-J)$ would have reflected this theme even if it had not been chosen by the conference committee, since both educational thinking and educational technology are so patently in flux.

Educational theory over the centuries has shown wild swings between, on the one hand, an approach based on rote learning and step-by-step dispensing of knowledge (politically safe and therefore the traditional route) and, on the other, one based on discovery and experiential learning (nearly always rejected by the establishment, at best after trial periods). At present, the direction of the pendulum is towards active learning, exploratory learning and so forth, and the wobbles I detect from time to time probably do not indicate an imminent swing in the opposite direction among educationists, since these wobbles are mostly caused by politicians.

Running parallel with this move towards learning centred on partnership, interactivity and discovery are the developments in learning technology with which ALT is so deeply concerned. But user-expectations are still largely ahead of what the technology can actually deliver. And herein lies the heart of the problem of the relationship between changing education and changing technology. Current educational thinking makes ever-increasing demands on a technology which, as often as not, is unequal to the task. Hence the lack of fullscreen, full-motion, fully interactive video in multimedia CAL software. Hence the inability of most examples of such software to distinguish between a serious student error and little more than a slip of the finger on the keyboard, let alone to see subtle implications in errors, implications which human teachers might easily sense. Hence the difficulties encountered in a number of Internet-related learning schemes: the supposed information superhighway can in reality be more like an information $B$ road.

So while I was hardly astonished that the majority of the papers given at the conference dealt in one way or another with changes in technology and/or reflected present trends in educational thinking, I was a little surprised that so few of them directly addressed what for me 
was the central implication of the conference's theme: the complex and potentially uneasy relationship between the two kinds of change.

Many papers described pieces of high-risk software - high-risk because it teeters on the edge of the capabilities of the technology available to most people, and because its effectiveness is as yet unproven. The history of information-delivery technology shows that as soon as a new form of it appears (chalk and slate, the printing press, tape recorders, overhead projectors, video tapes, computer-controlled presentations, data communications ... .), teachers try to take advantage of its educational possibilities, with varying degrees of success. There is of course nothing intrinsically wrong in the desire to tread new ground; after all, if Columbus had waited until it was perfectly safe to travel by sea, he would not have found America. On the other hand, we are dealing here not with, say, medical research where doctors try out risky techniques on patients who would otherwise die because there is no alternative treatment, but rather with an area offering a whole range of well-tried methods.

Changing education is not always a consequence of changing technology, nor vice-versa. The links between the two, inextricable though they are, are far from straightforward, and we who consider ourselves at the forefront of educational thinking should constantly be on our guard against the dangerous view that they must necessarily move forward hand in hand. Who dares wins may be the motto of the SAS, but we are not in their business.

\section{Gabriel Jacobs}

